\title{
Limited root repair in acute type A aortic dissection is safe but results in increased risk of reoperation
}

\author{
Peter Chiu, MD, MS, a,b Jeffrey Trojan, BA, ${ }^{a}$ Sarah Tsou, BA, ${ }^{a}$ Andrew B. Goldstone, MD, PhD,,${ }^{\mathrm{a}, \mathrm{b}}$ \\ Y. Joseph Woo, MD, and Michael P. Fischbein, MD, PhD ${ }^{\mathrm{a}}$
}

\section{ABSTRACT}

Objective: Management of the aortic root is a challenge for surgeons treating acute type A aortic dissection.

Methods: We performed a retrospective review of the acute type A aortic dissection experience at Stanford Hospital between 2005 and 2015 and identified patients who underwent either limited root repair or aortic root replacement. Differences in baseline characteristics were balanced with inverse probability weighting to estimate the average treatment effect on the controls. Weighted logistic regression was used to evaluate in-hospital mortality. Weighted Cox proportional hazards regression was used to evaluate differences in the hazard for mid-term death. Reoperation was evaluated with death as a competing risk with the Fine-Gray subdistribution hazard.

Results: After we excluded patients managed either nonoperatively or with definitive endovascular repair, there were 293 patients without connective tissue disease who underwent either limited root repair or aortic root replacement. There was no difference in weighted perioperative mortality, odds ratio $0.89(95 \%$ confidence interval $[\mathrm{CI}], 0.44-1.76, P=.7)$, and there was no difference in weighted survival, hazard ratio $1.12(95 \% \mathrm{CI}, 0.54-2.31, P=.8)$. Risk of reoperation was greater in limited root repair $(11.8 \%, 95 \% \mathrm{CI}, 0.0 \%-23.8 \%)$ than for root replacement $(0 \%), P<.001$.

Conclusions: Limited root repair was associated with increased risk of late reoperation after repair of acute type A aortic dissection. Surgeons with adequate experience may consider aortic root replacement in well-selected patients. However, given good outcomes after limited root repair, surgeons should not feel compelled to perform this more-complex operation. (J Thorac Cardiovasc Surg 2018;155:1-7)

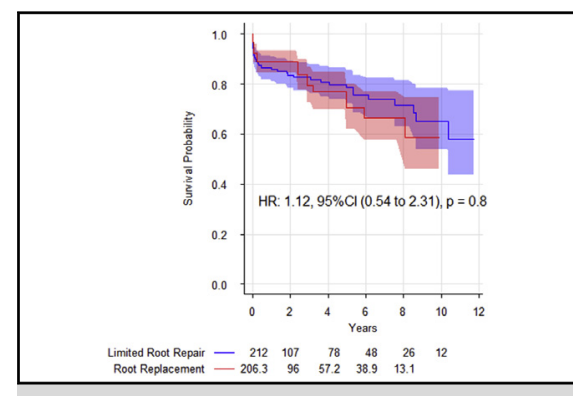

There was no survival difference between aortic root replacement and limited root repair.

\section{Central Message}

Aortic root replacement reduces the risk for late reoperation compared with limited root repair in acute type A aortic dissection, but survival is no different.

\section{Perspective}

Appropriate management of the aortic root in acute type A aortic dissection remains uncertain. This study reports the adequacy of limited root repair in acute type A aortic dissection but also underlines the increased risk of reoperation with the more-conservative approach.

See Editorial Commentary page 8 .
Acute type A aortic dissection is a life-threatening process that has remained a persistent challenge for cardiovascular surgeons. In the International Registry of Acute Aortic Dissection, perioperative mortality remains high, at

\footnotetext{
From the ${ }^{\mathrm{a}}$ Department of Cardiothoracic Surgery, and ${ }^{\mathrm{b}}$ Division of Health Research and Policy, Stanford University, School of Medicine, Stanford, Calif.

This work was supported by a National Institutes of Health, National Center for Advancing Translational Science, Clinical and Translational Science Award (Dr Chiu, KL2 TR000083; Dr Goldstone, TL1 TR000084 and UL1 TR001085). The content is solely the responsibility of the authors and does not necessarily represent the official views of the National Institutes of Health

Received for publication May 10, 2017; revisions received June 28, 2017; accepted for publication Aug 24, 2017; available ahead of print Oct 15, 2017.

Address for reprints: Michael P. Fischbein, MD, PhD, Falk CVRB, 300 Pasteur Dr, Falk CVRB ULN MC5407, Stanford, CA 94305 (E-mail: mfischbe@ stanford.edu). 0022-5223/\$0.00

Copyright (C) 2017 by The American Association for Thoracic Surgery. This is an open access article under the CC BY-NC-ND license (http://creativecommons.org/ licenses/by-nc-nd/4.0/).

https://doi.org/10.1016/j.jtcvs.2017.08.137
}

$18.4 \%{ }^{1}$ Consolidation of care to a focused team experienced with the particular challenges of these complex patients may improve outcomes, with perioperative mortality ranging from $9 \%$ to $16.4 \%,{ }^{2-5}$ but the call for regionalization has not yet been answered.

One of the perennial challenges confronting the surgeon tasked with the care of a patient with acute type A aortic dissection has been the appropriate management of the aortic root. ${ }^{4,5,7-11}$ The pendulum has swung from aggressive replacement of the root in all patients to conservative root repair and back again. ${ }^{6}$ With the emerging evidence that

Uf $\begin{aligned} & \text { Scanning this QR code will take } \\ & \text { you to supplemental table for } \\ & \text { this article. }\end{aligned}$




\section{Abbreviations and Acronyms \\ $\mathrm{CI}=$ confidence interval \\ $\mathrm{HR}=$ hazard ratio}

operative volume affects outcome in operations of the proximal aorta, ${ }^{12}$ the role for each strategy (limited root repair vs aortic root replacement) has again been brought under the microscope. We undertook the current study to evaluate the effectiveness of limited root repair and aortic root replacement in patients with acute type A aortic dissection.

\section{METHODS}

This was a retrospective review of consecutive patients undergoing operative repair of acute type A aortic dissection at Stanford Hospital between January 2005 and December 2015. After approval from the institutional review board at Stanford University (IRB-32951, date of last approval January 31, 2017), we used internal departmental databases and a query of billing data using the Stanford Translational Research Integrated Database to discover patients treated for acute type A aortic dissection at our institution. Patients undergoing definitive endovascular repair were excluded. In addition, those with Marfan or similar syndromes (strong indication for root replacement) were excluded. ${ }^{13}$ We identified the subset of patients for whom an intervention on the aortic root was performed. Limited root repair was defined as aortic valve resuspension, sinotubular junction reconstruction, use of biological glue in the dissected root, felt neomedia repair, or Yacoub aortic root remodeling of 1 or 2 sinuses. Aortic root replacement was defined as valve-sparing aortic root replacement or root replacement with either a composite valve graft or porcine xenograft (Freestyle; Medtronic Inc, Minneapolis, Minn).

Continuous variables are presented as mean with standard deviation or median with interquartile range. Categorical variables are presented as absolute counts with percentages. All hazard ratios and odds ratios (ORs) are presented with $95 \%$ confidence intervals (CIs). The analysis was conducted with R-3.2.2 (R Foundation for Statistical Computing, Vienna, Austria). A $P$ value of $<.05$ was considered statistically significant; all $P$ values are 2 -sided. Because of the exploratory nature of this analysis, no adjustment was made for multiple comparisons. ${ }^{14}$

\section{Inverse Probability Weighting With the Propensity Score}

A nonparsimonious logistic regression model was used to estimate the probability of aortic root replacement (Table E1), and inverse probability weighting was used to estimate the average treatment effect on the controls (treatment weight: $[1$ - propensity score]/propensity score; control weight: 1). ${ }^{15-17} \mathrm{We}$ undertook estimation of the average treatment effect on the controls due to the lack of strict exchangeability, ie, patients who underwent aortic root replacement were not necessarily eligible to undergo limited root repair. This allowed for the creation of a pseudo-population of patients undergoing aortic root replacement similar to the unweighted population of patients undergoing limited root repair. In this way, we evaluated the possible effect of aortic root replacement on the patients who underwent limited root repair. Patients who were dialysis dependent were excluded at this stage because of our inability to construct groups with appropriate balance. Balance was assessed with the standardized mean differences approach; a standardized mean difference less than 0.2 was considered to be acceptable balance. ${ }^{18}$

\section{Survival Analysis}

Our primary outcome of interest was mid-term survival. Weighted Cox proportional hazards regression with a robust variance estimator was used to compare overall survival between patients undergoing limited root repair and aortic root replacement. To account for potential differences between individual surgeons, a mixed-effects Cox model was constructed with surgeon as a random intercept in a separate analysis. Adjusted survival curves were constructed via the technique of Cole and Hernan. ${ }^{19}$

The secondary outcomes of interest were perioperative mortality, which was defined by death before discharge during the index hospitalization, and reoperation on either the aortic root or aortic valve. Weighted logistic regression with a robust variance estimator was used to compare inhospital mortality. Reoperation on the root or valve was evaluated with death as a competing risk by estimating the subdistribution hazard with a weighted form of the Fine-Gray technique. ${ }^{20}$

Clinical follow-up of patients with aortic pathology at Stanford is maintained by a thoracic aortic monitoring program with a dedicated group of advanced practice practitioners, administrative staff, surgeons, and radiologists. Mortality is evaluated via a combination of Social Security Death Index, integration of electronic medical record with regional health systems, and direct patient contact. Our process is similar to that reported by the Yale group ${ }^{21}$; our efforts are aided greatly by the presence of a large integrated managed care consortium in northern California.

\section{RESULTS}

There were 391 patients with acute type A aortic dissection who presented to our institution between 2005 and $2015 ; 31$ patients $(7.9 \%)$ were managed nonoperatively, $15(3.8 \%)$ were primarily treated with endovascular repair, and $345(88.2 \%)$ patients underwent open surgical repair. Of the patients who underwent open repair, there were 323 patients who underwent root intervention of any form and thus were eligible for inclusion in our study. Of these patients, there were 23 patients with Marfan or a similar syndrome, and there were 7 patients who were dialysis dependent. After we excluded these patients, there were 293 patients eligible for analysis. Median follow-up was 2.1 years (interquartile range $0.4-5.2$ years). The majority of patients underwent an operation within 24 hours of symptom development $(226 ; 77.1 \%)$, and 273 patients $(93.2 \%)$ were transferred from another institution.

In general, patients who underwent aortic root replacement $(\mathrm{n}=81 ; 27.6 \%)$ were younger and had fewer chronic comorbidities than patients who underwent a limited root repair $(n=212 ; 72.4 \%)$. However, patients undergoing aortic root replacement presented more frequently with shock physiology manifested by persistent hypotension with or without the need for pressor support $(\mathrm{n}=15$; $18.5 \%)$ compared with limited root repair $(n=20$; $9.4 \%$ ). Inverse probability weighting appropriately controlled for observed differences in baseline covariates (Table 1).

Before weighting, patients undergoing limited root repair had shorter cardiopulmonary bypass time and shorter aortic crossclamp time than those undergoing aortic root replacement. After weighting, these differences remained. Before weighting, most patients $(89.4 \%)$ received blood or blood products. Patients undergoing aortic root replacement had a greater intraoperative blood product requirement in the weighted comparison, but packed red blood cell transfusion 
TABLE 1. Demographic and clinical characteristics

\begin{tabular}{|c|c|c|c|c|c|c|}
\hline & $\frac{\text { Limited root repair }}{n=212}$ & $\frac{\text { Aortic root replacement }}{n=81}$ & SMD & $\frac{\text { Limited root repair }}{n=212}$ & $\frac{\text { Aortic root replacement }}{\mathrm{n}=206.3}$ & SMD \\
\hline \multicolumn{7}{|l|}{ Demographics } \\
\hline Operative year, median [IQR] & 2011 [2008, 2013] & 2012 [2009, 2014] & 0.308 & 2011 [2008, 2013] & $2010.62[2009,2013]$ & 0.171 \\
\hline Age, mean $(\mathrm{SD})$ & $60.98(12.71)$ & $57.40(13.08)$ & 0.278 & $60.98(12.71)$ & $61.25(14.15)$ & 0.020 \\
\hline Female, $\mathrm{n}(\%)$ & $71(33.5)$ & $14(17.3)$ & 0.379 & $(33.5)$ & (25.4) & 0.178 \\
\hline White, n (\%) & $109(51.4)$ & $51(63.0)$ & 0.235 & $(51.4)$ & (48.7) & 0.054 \\
\hline Black, n (\%) & $13(6.1)$ & $5(6.2)$ & 0.002 & $(6.1)$ & $(8.8)$ & 0.103 \\
\hline \multicolumn{7}{|l|}{ Clinical characteristics } \\
\hline Previous stroke, n (\%) & $7(3.3)$ & $3(3.7)$ & 0.022 & (3.3) & (1.1) & 0.152 \\
\hline Heart failure, $\mathrm{n}(\%)$ & $8(3.8)$ & $7(8.6)$ & 0.203 & (3.8) & $(5.9)$ & 0.098 \\
\hline Coronary artery disease, $\mathrm{n}(\%)$ & $22(10.4)$ & $7(8.6)$ & 0.059 & $(10.4)$ & $(14.0)$ & 0.112 \\
\hline Atrial fibrillation, $\mathrm{n}(\%)$ & $15(7.1)$ & $5(6.2)$ & 0.036 & $(7.1)$ & $(9.1)$ & 0.074 \\
\hline Hypertension, n (\%) & $190(89.6)$ & $65(80.2)$ & 0.264 & $(89.6)$ & $(83.9)$ & 0.169 \\
\hline Hyperlipidemia, n (\%) & $66(31.1)$ & $17(21.0)$ & 0.233 & $(31.1)$ & $(24.6)$ & 0.145 \\
\hline COPD, n (\%) & 33 (15.6) & $6(7.4)$ & 0.258 & (15.6) & (17.7) & 0.058 \\
\hline Home oxygen, $\mathrm{n}(\%)$ & $3(1.4)$ & $0(0.0)$ & 0.169 & $(1.4)$ & $(0.0)$ & 0.169 \\
\hline Diabetes, n (\%) & $17(8.0)$ & $1(1.2)$ & 0.327 & $(8.0)$ & (4.5) & 0.146 \\
\hline Chronic renal insufficiency, $\mathrm{n}(\%)$ & $31(14.6)$ & $7(8.6)$ & 0.187 & (14.6) & (10.6) & 0.122 \\
\hline Bicuspid aortic valve, n (\%) & $5(2.4)$ & $15(18.5)$ & 0.548 & (2.4) & (2.4) & $<0.001$ \\
\hline Previous sternotomy, n (\%) & $11(5.2)$ & $3(3.7)$ & 0.072 & $(5.2)$ & $(9.5)$ & 0.166 \\
\hline \multicolumn{7}{|l|}{ Characteristics at presentation } \\
\hline Extensive type A, n (\%) & $191(90.1)$ & $69(85.2)$ & 0.150 & $(90.1)$ & $(87.1)$ & 0.095 \\
\hline $3+$ or greater AI, n (\%) & $65(30.7)$ & $41(50.6)$ & 0.415 & $(30.7)$ & $(33.6)$ & 0.063 \\
\hline Malperfusion, n (\%) & $53(25.0)$ & $22(27.2)$ & 0.049 & $(25.0)$ & $(22.1)$ & 0.068 \\
\hline Shock, n (\%) & $20(9.4)$ & $15(18.5)$ & 0.264 & $(9.4)$ & $(9.4)$ & 0.001 \\
\hline Neurologic deficit, n (\%) & $20(9.4)$ & $9(11.1)$ & 0.055 & (9.4) & $(10.5)$ & 0.036 \\
\hline
\end{tabular}

$S M D$, Standardized mean difference; $I Q R$, interquartile range; $S D$, standard deviation; $C O P D$, chronic obstructive pulmonary disease; $A I$, aortic insufficiency.

was no different (Table 2). There was no difference in mediastinal re-exploration for bleeding between limited root repair and root replacement in the weighted comparison $(9.4 \%$ vs $15.8 \%, P=.2)$.

In the limited root repair group, 158 (74.5\%) underwent aortic valve resuspension or sinotubular junction reconstruction, $29(13.7 \%)$ underwent felt neomedia repair, and $12(5.7 \%)$ underwent uni-Yacoub repair. There were $11(5.2 \%)$ patients who underwent aortic valve replacement as a separate valve graft. Biological glue was incorporated into $150(70.8 \%)$ of limited root repairs; the use of biological glue significantly declined over time from a peak of $83.3 \%$ in 2005 to $36 \%$ in 2014 , OR 0.85 per year $(95 \%$ CI, 0.79-0.92). Within the root-replacement group, there were 3 valve-sparing aortic root replacements; the majority $(n=42 ; 51.9 \%)$ of root replacements were mechanical composite valve grafts, and a minority were biological composite valve grafts $(\mathrm{n}=14 ; 17.3 \%)$ or Freestyle porcine xenografts $(\mathrm{n}=22 ; 27.2 \%)($ Table 3$)$.

TABLE 2. Operative characteristics

\begin{tabular}{lccc}
\hline & $\frac{\text { Limited root repair }}{\mathbf{n}=\mathbf{2 1 2}}$ & $\frac{\text { Root replacement }}{\mathbf{n}=\mathbf{2 0 6 . 3}}$ & $\boldsymbol{P}$ value \\
\hline Cardiopulmonary bypass time & $204.04(54.24)$ & $278.97(74.38)$ & $<.001$ \\
Aortic crossclamp time & $117.63(39.95)$ & $195.23(56.52)$ & $<.001$ \\
Total cerebral protection time & $29.65(12.62)$ & $28.48(10.31)$ & \\
Intraoperative transfusion requirement & & $2.37[0,6]$ & .6 \\
Red cells, median [IQR] & $2[0,5]$ & $8[6,12]$ & $3[2,4]$ \\
FFP, median [IQR] & $6[4,8]$ & $1[0,3.08]$ & .3 \\
Platelets, median $[\mathrm{IQR}]$ & $2[2,3]$ & $0[0,2]$ & .001 \\
Cryoprecipitate, median $[\mathrm{IQR}]$ & & .009 \\
\hline
\end{tabular}

$I Q R$, Interquartile range; $F F P$, fresh-frozen plasma. 
TABLE 3. Techniques used in repair and replacement of the aortic root

\begin{tabular}{lcc}
\hline \multicolumn{1}{c}{ Technique } & Limited root repair & $\begin{array}{c}\text { Root } \\
\text { replacement }\end{array}$ \\
\hline $\begin{array}{l}\text { Root and valve repair techniques } \\
\text { Valve resuspension/STJ }\end{array}$ & $157(74.1 \%)$ & \\
$\quad$ reconstruction & & \\
Felt neomedia & $29(13.7 \%)$ & \\
Uni-Yacoub & $12(5.7 \%)$ & \\
Aortic valve replacement & $11(5.2 \%)$ & \\
Aortic valve cusp repair & $6(2.8 \%)$ & \\
Root-replacement techniques & & $42(51.9 \%)$ \\
Mechanical CVG & & $14(17.3 \%)$ \\
Bioprosthetic CVG & & $22(27.2 \%)$ \\
Freestyle & & $3(3.7 \%)$ \\
VSARR & & \\
\hline
\end{tabular}

$S T J$, Sinotubular junction; $C V G$, composite valve graft; $V S A R R$, valve-sparing aortic root replacement.

Perioperative mortality was low for both groups, ie, limited root repair $(19 ; 9.0 \%)$ and root replacement $(9 ; 11.1 \%)$. There was no increase in the weighted odds of in-hospital mortality with aortic root replacement, OR 0.89 (95\% CI, 0.44-1.76, $P=.7$ ) (Table 4). In addition, aortic root replacement was not associated with increased risk of mid-term mortality compared with limited root replacement after inverse probability weighting, hazard ratio $1.12(95 \% \mathrm{CI}, 0.54-2.31, P=.8)$ (Table 4, Figure 1$)$.

The risk of reoperation on the aortic root and aortic valve was greater in patients undergoing limited root repair $(11.8 \%$; 95\% CI, $0.0 \%-23.8 \%)$ than for root replacement $(0 \%), P<.001$ (Figure 2). The unweighted median time to reoperation was 2.3 years (range: 7 days to 10.2 years). Five of the 6 reoperations $(83.3 \%)$ in limited root repair patients had incorporated biological glue in the repair. Three patients $(50 \%)$ required aortic root replacement at the time of reoperation, and the remaining 3 required aortic

TABLE 4. Perioperative mortality and mid-term survival comparing aortic root replacement with limited root repair (reference)

\begin{tabular}{lccc}
\hline & Estimate & $\mathbf{9 5} \% \mathbf{C I}$ & $\boldsymbol{P}$ value \\
\hline $\begin{array}{l}\text { Perioperative mortality, odds ratio } \\
\quad \text { Logistic regression } \\
\quad \text { (unadjusted) }\end{array}$ & 1.27 & $0.55-2.94$ & .6 \\
$\begin{array}{l}\text { Weighted logistic } \\
\quad \text { regression }\end{array}$ & 0.89 & $0.44-1.76$ & .7 \\
$\begin{array}{l}\text { Mid-term survival, hazard ratio } \\
\quad \text { Cox, univariable } \\
\quad \text { (unweighted) } \\
\begin{array}{l}\text { Cox, univariable } \\
\quad \text { (weighted) }\end{array}\end{array}$ & 1.18 & $0.66-2.10$ & .6 \\
$\quad \begin{array}{l}\text { Cox, mixed effects } \\
\quad \text { (weighted) }\end{array}$ & 1.12 & $0.54-2.31$ & .8 \\
\hline
\end{tabular}

Reference: limited root repair. $C I$, Confidence interval.

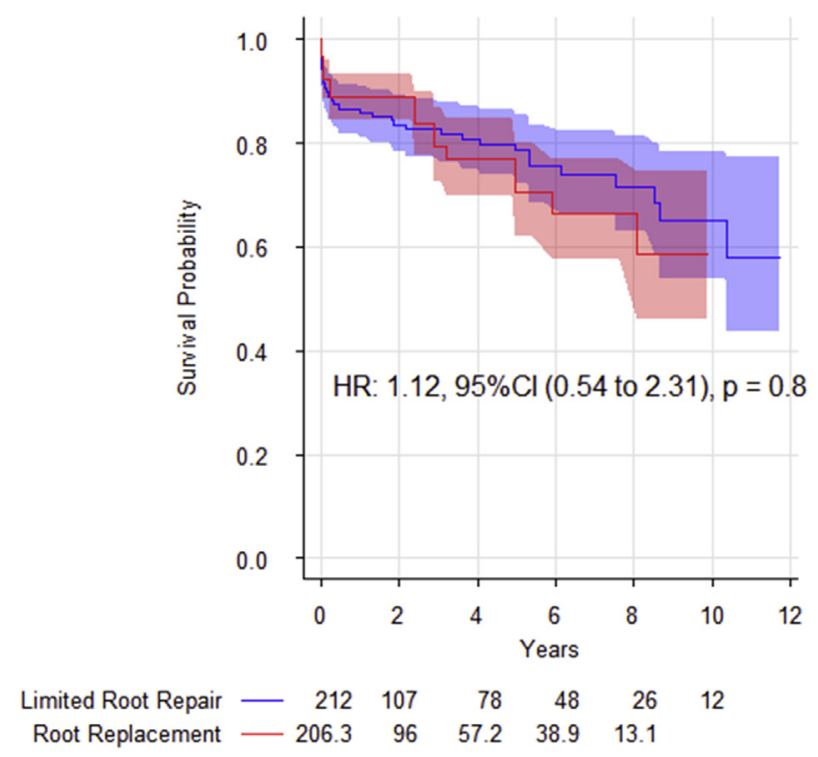

FIGURE 1. Adjusted survival curves comparing limited root repair (blue) with aortic root replacement (red). Shading represents $95 \%$ CIs. There was no significant difference in mid-term survival between the approaches. $H R$, Hazard ratio; $C I$, confidence interval.

valve replacements for aortic insufficiency (Table 5). There were no perioperative deaths after reoperation.

\section{DISCUSSION}

Management of the aortic root in acute type A aortic dissection has undergone a substantial evolution over time, but the existing literature comparing limited root repair with aortic root replacement is becoming dated. ${ }^{6,9-11}$ Given the good outcomes reported with neomedia sinus of

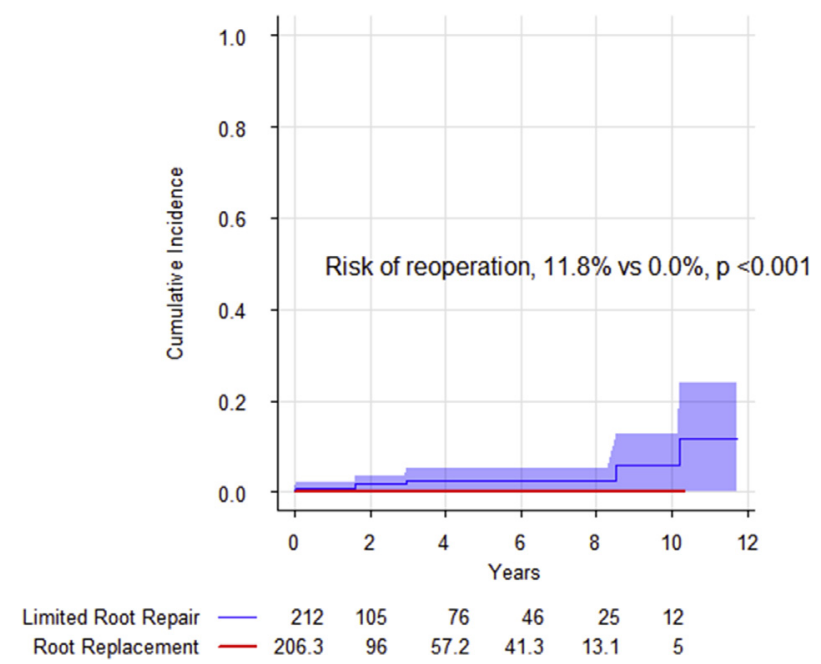

FIGURE 2. Risk of reoperation, with death as a competing risk, comparing limited root repair (blue) with aortic root replacement (red). Shading represents $95 \%$ confidence intervals. Limited root repair was associated with an increased risk of reoperation. 
TABLE 5. Table of reoperations

\begin{tabular}{llcll}
\hline Year & \multicolumn{1}{c}{ Index operation on the proximal aorta } & Years to reoperation & Reason for reoperation & $\begin{array}{c}\text { Grade of aortic } \\
\text { insufficiency at reoperation }\end{array}$ \\
\hline 2005 & Aortic valve resuspension, biological glue & 10.19 & Concomitant arch reoperation & $2+$ \\
2005 & Supracoronary repair, biological glue & 8.53 & Aortic insufficiency & $4+$ \\
\hline 2007 & Aortic valve resuspension, biological glue & 0.05 & Early aortic insufficiency & $3+$ \\
2009 & Uni-Yacoub and STJ remodeling, biological glue & 0.02 & Early aortic insufficiency & $3+$ \\
2013 & Aortic valve resuspension & 2.98 & Root aneurysm & $2+$ \\
\hline 2015 & Aortic valve resuspension, biological glue & 1.61 & Pseudoaneurysm & $2+$ \\
\hline
\end{tabular}

STJ, Sinotubular junction.

Valsalva repair, ${ }^{4}$ revisiting the comparative effectiveness of these 2 strategies is timely. We found that at a tertiary aortic referral center, perioperative mortality was low, and there was no difference between limited root repair and aortic root replacement in either perioperative mortality or mid-term survival. Aortic root replacement was associated with longer operative times and increased intraoperative blood product requirement. However, aortic root replacement also reduced the risk for mid-term reoperation on the aortic valve and aortic root. Given the increased complexity of aortic root replacement, a more aggressive strategy should only be undertaken by surgeons with adequate experience in patients most likely to benefit from this approach.

\section{Does Root Repair Increase the Risk for Reoperation?}

Typical indications for aortic root replacement are the following: existing aortic root aneurysm, connective tissue disease, extensive destruction of the sinuses, and destruction of the coronary ostia. The need for clarity on patient and procedure selection has never been greater than it is now, given the excellent outcomes reported by several institutions using widely varying techniques. Reports range from the minimalist approach at the Mayo Clinic, where one third of patients received an isolated supracoronary graft with no intervention on the root; to $80 \%$ undergoing felt neomedia repair at Penn; to the aggressive approach at Emory, where $12 \%$ underwent valve-sparing aortic root replacement. ${ }^{4,5,22}$

In the Mayo Clinic experience spanning 42 years, Wang and colleagues ${ }^{5}$ reported that root replacement did not result in an increased risk of perioperative mortality. However, aortic root replacement did not reduce the risk of late reoperation. In their report, the Mayo group voiced concerns about the use of retrospective observational studies in evaluating the comparative effectiveness of limited root repair and aortic root replacement, and the 42-year study period under consideration introduced the potential for a secular trend. Di Eusanio and colleagues ${ }^{11}$ used propensity score adjustment to address the potential issue of treatment selection bias in a multivariable regression analysis of the International Registry of Acute Aortic Dissection. They also reported no difference in mortality and no difference in aortic root reoperation. However, the limited follow-up in their multi-institutional prospective registry reduced the ability to observe the effect of the 2 approaches on reoperation, which has a tendency to occur beyond the 3 -year interval under examination in their study. We hope that our results using a large cohort of patients during a contemporary period while also using causal inference methods may provide greater clarity to the question of whether limited root repairs contribute increased risk of late reoperation.

In patients undergoing limited root repair, our group uses a variety of techniques to repair the root, and these-as a group-were associated with an increased risk of reoperation in the mid-term. We speculate that this may be due to the diseased tissue that is left behind after a limited root repair. However, the degree to which this must be addressed is uncertain, given that the majority of patients undergoing a limited root repair may not have derived any benefit from a more extensive operation during the observed follow-up time. Interestingly, the valve itself was as often the issue as the aortic root, an experience that is similar to other series that have examined the durability of aortic root repair techniques. ${ }^{4}$ As such, long-term valve-related considerations including expected patient longevity and whether a truly durable valve repair is possible must be balanced against the potential morbidity associated with aortic valve replacement when choosing between limited root repair and aortic root replacement. Among these considerations must include the possibility for valve-related reoperation, especially with bioprosthetic valves. Our data had limited follow-up beyond 10 years, the time period around which valverelated failure might be expected to increase the incidence of reoperation.

\section{Procedure Selection}

Procedure selection is controversial both in terms of limited root repair and aortic root replacement. Biological glues once held great promise in reducing the complexity of operations for acute type A aortic dissection. ${ }^{23}$ However, in recent years, evidence of glue-related complications reported in the literature-and our own experience with 
reoperative surgery after acute type A aortic dissection repair, many of whom had their primary operation at other institutions - have tempered our early enthusiasm for these products. ${ }^{24,25}$ The use of biological glues has declined substantially over time at Stanford as a result. Whether any of the reparative techniques is superior to others is uncertain, and our study was not of sufficient size or granularity to evaluate this question.

The decision to perform valve-sparing aortic root replacement, mechanical composite valve graft, biological composite valve graft, or stentless xenograft is a separate challenge. The perfect replacement for the patient's own aortic valve has not yet been invented. Young patients will benefit from either a mechanical composite valve graft or valve-sparing aortic root replacement, although the added complexity and procedural duration associated with the latter operation suggests that only very experienced practitioners should undertake this operation in highly selected patients. When a valve-sparing technique is used, good results have been reported for both the remodeling (Yacoub) and reimplantation (David) techniques, ${ }^{22,26}$ but our preference is for a reimplantation approach. In older patients and patients unable to be anticoagulated, biological prostheses may be either stentless xenografts or stented valves mounted in a Dacron graft on the backtable. Stented valves have excellent long-term durability reported in older patients, ${ }^{27,28}$ and these valves offer the possibility of transcatheter valve-in-valve replacement in the event of structural valve degeneration. ${ }^{29}$ In contrast, stentless xenografts represent a special challenge for valve-in-valve techniques, ${ }^{30,31}$ and for this reason our group has moved away from these prostheses.

\section{Surgeon and Institution Factors}

The current evidence suggests that experience is a major contributing factor in the outcome of surgery on the proximal aorta. ${ }^{3,12}$ The majority of institutions perform fewer than 6 aortic root replacements or separate valve grafts in the elective setting per year. ${ }^{12}$ Furthermore, the majority of institutions treating aortic dissection (both type A and type B) are not high-volume referral centers: Chikwe and colleagues $^{32}$ reported that $73.4 \%$ of patients were treated at centers performing 13 or fewer aortic dissection cases per year. In light of this, any recommendation for operative management must be in the context of surgeon and institutional experience. For most surgeons and institutions, a conservative approach to the root to limit the complexity of the case and operative time may be justifiable whenever possible-including potentially for patients who might have indications for root replacement, although this is somewhat speculative-given that perioperative mortality can be less than $10 \%$ and mid-term survival does not appear to be affected. Having a survivor at the end of the operation is always the first priority, and surgeons with limited experience in performing aortic root replacements may be doing their patients a service with a less-aggressive operation. These patients require close follow-up, given the risk for root and valve reoperation, and enrollment in a thoracic aortic monitoring program at an aortic referral center should be considered for these patients. In this way, surgeon and institutional characteristics may affect operative strategy as much as patient-specific and dissection-related factors.

\section{Reoperation}

Although our series of patients had a low incidence of perioperative mortality after reoperation on the aortic root, the risk associated with reoperation is substantial. Perioperative mortality for reoperation on the aortic root after previously repaired acute type A aortic dissection has been reported to be between $6.4 \%$ and $23.5 \%{ }^{4,33}$ As such, the risk associated with reoperation ought to be weighed against the increased complexity and longer procedure time associated with aortic root replacement. For surgeons with adequate experience, the more aggressive operation may prevent a high-risk reoperation in almost 1 in 8 patients at 8 to 10 years without increasing the operative risk, although whether an $11.8 \%$ risk of reoperation at 10 years is meaningful is up to the individual surgeon. Conversely, surgeons who do not routinely perform aortic root operations may consider performing the more expedient operation in the absence of absolute indications for aortic root replacement. This may ensure survival to discharge, given the potential to achieve low perioperative mortality with a limited root repair approach. Ongoing follow-up at an aortic referral center for possible reoperation is absolutely necessary for patients undergoing limited root repair.

\section{Limitations and Strengths}

This was a retrospective study of a single tertiary referral center for aortic diseases, and whether the results with aortic root surgery are truly generalizable to the greater community is uncertain. Our finding that a limited root repair may be performed with less than $10 \%$ mortality and mid-term survival no different from aortic root replacement suggests that surgeons with limited experience with aortic dissection and aortic root replacement should not feel compelled to perform the more-complex operation in the emergent setting. Rather than relying primarily on patient-specific and dissection-related factors-as recommended by Di Eusanio and colleagues ${ }^{11}$ - surgeon and institutional characteristics also may need to be taken into consideration; this may-in turn-support regionalization of care. However, our study was inadequate in both size and scope to evaluate the effect of such a policy.

Despite these limitations, this study benefited from being limited to a contemporary period, thus reducing the effect of a secular trend in care. The use of causal inference 
techniques to mitigate the effect of treatment selection bias on our analysis is another significant strength. Finally, the use of competing risks methods to assess the risk of reoperation is critical, given that death is a form of informative censoring, and the Kaplan-Meier method, which frequently is used in the cardiovascular surgery literature, is not appropriate.

\section{CONCLUSIONS}

At a tertiary aortic referral center, aortic root replacement was not associated with a greater risk of mortality than limited root repair for acute type A aortic dissection. Limited root repair-although a safe option in appropriately selected patients-incurred an increase in the risk of reoperation, suggesting that close surveillance is required for these patients. Among surgeons with adequate experience, a more aggressive approach to the aortic root may be warranted to avoid subsequent reoperation in wellselected patients. However, surgeons who do not perform aortic root operations on a routine basis should not feel compelled to perform the more extensive operation.

\section{Conflict of Interest Statement}

Dr Fischbein has received speaking honoraria from St Jude. In addition, he receives funding from the National Institutes of Health (NIH R01AR066629-01A1). All other authors have nothing to disclose with regard to commercial support.

\section{References}

1. Pape LA, Awais M, Woznicki EM, Suzuki T, Trimarchi S, Evangelista A, et al. Presentation, diagnosis, and outcomes of acute aortic dissection: 17-year trends from the International Registry of Acute Aortic Dissection. J Am Coll Cardiol. 2015;66:350-8

2. Bavaria JE, Pochettino A, Brinster DR, Gorman RC, McGarvey ML, Gorman JH, et al. New paradigms and improved results for the surgical treatment of acute type A dissection. Ann Surg. 2001;234:336-42; discussion 342-3.

3. Andersen ND, Ganapathi AM, Hanna JM, Williams JB, Gaca JG, Hughes GC. Outcomes of acute type a dissection repair before and after implementation of a multidisciplinary thoracic aortic surgery program. J Am Coll Cardiol. 2014; 63:1796-803.

4. Rylski B, Bavaria JE, Milewski RK, Vallabhajosyula P, Moser W, Kremens E, et al. Long-term results of neomedia sinus valsalva repair in 489 patients with type A aortic dissection. Ann Thorac Surg. 2014;98:582-8; discussion 588-9.

5. Wang Z, Greason KL, Pochettino A, Schaff HV, Suri RM, Stulak JM, et al. Long-term outcomes of survival and freedom from reoperation on the aortic root or valve after surgery for acute ascending aorta dissection. J Thorac Cardiovasc Surg. 2014;148:2117-22.

6. Chiu P, Miller DC. Evolution of surgical therapy for Stanford acute type A aortic dissection. Ann Cardiothorac Surg. 2016;5:275-95.

7. Appelbaum A, Karp RB, Kirklin JW. Ascending vs descending aortic dissections. Ann Surg. 1976;183:296-300.

8. Yun KL, Miller C. Technique of aortic valve preservation in acute type A aortic dissection. Op Tech Cardiac Thorac Surg. 1996;1:68-81.

9. Sabik JF, Lytle BW, Blackstone EH, McCarthy PM, Loop FD, Cosgrove DM. Long-term effectiveness of operations for ascending aortic dissections. J Thorac Cardiovasc Surg. 2000;119:946-62.

10. Halstead JC, Spielvogel D, Meier DM, Rinke S, Bodian C, Malekan R, et al. Composite aortic root replacement in acute type A dissection: time to rethink the indications? Eur J Cardiothorac Surg. 2005;27:626-32; discussion 632-3.
11. Di Eusanio M, Trimarchi S, Peterson MD, Myrmel T, Hughes GC, Korach A, et al. Root replacement surgery versus more conservative management during type A acute aortic dissection repair. Ann Thorac Surg. 2014;98:2078-84.

12. Hughes GC, Zhao Y, Rankin JS, Scarborough JE, O’Brien S, Bavaria JE, et al Effects of institutional volumes on operative outcomes for aortic root replacement in North America. J Thorac Cardiovasc Surg. 2013;145:166-70.

13. Rylski B, Bavaria JE, Beyersdorf F, Branchetti E, Desai ND, Milewski RK, et al. Type A aortic dissection in Marfan syndrome: extent of initial surgery determines long-term outcome. Circulation. 2014;129:1381-6.

14. Rothman KJ. No adjustments are needed for multiple comparisons Epidemiology. 1990;1:43-6.

15. Robins JM, Hernan MA, Brumback B. Marginal structural models and causal inference in epidemiology. Epidemiology. 2000;11:550-60.

16. Austin PC, Stuart EA. Moving towards best practice when using inverse probability of treatment weighting (IPTW) using the propensity score to estimate causal treatment effects in observational studies. Stat Med. 2015;34 3661-79.

17. Austin PC. An introduction to propensity score methods for reducing the effects of confounding in observational studies. Multivariate Behav Res. 2011;46: 399-424.

18. Silber JH, Rosenbaum PR, Trudeau ME, Even-Shoshan O, Chen W, Zhang X, et al. Multivariate matching and bias reduction in the surgical outcomes study Med Care. 2001;39:1048-64.

19. Cole SR, Hernan MA. Constructing inverse probability weights for margina structural models. Am J Epidemiol. 2008;168:656-64.

20. Fine JP, Gray RJ. A proportional hazards model for the subdistribution of a competing risk. J Am Stat Assoc. 1999;94:496-509.

21. Peterss S, Charilaou P, Ziganshin BA, Elefteriades JA. Assessment of survival in retrospective studies: the Social Security Death Index is not adequate for estimation. J Thorac Cardiovasc Surg. 2017;153:899-901.

22. Leshnower BG, Myung RJ, McPherson L, Chen EP. Midterm results of David V valve-sparing aortic root replacement in acute type A aortic dissection. Ann Thorac Surg. 2015;99:795-800; discussion 800-1.

23. Bachet J, Goudot B, Dreyfus GD, Brodaty D, Dubois C, Delentdecker P, et al Surgery for acute type A aortic dissection: the Hopital Foch experience (1977-1998). Ann Thorac Surg. 1999;67:2006-9; discussion 2014-9.

24. Kazui T, Washiyama N, Bashar AH, Terada H, Suzuki K, Yamashita K, et al. Role of biologic glue repair of proximal aortic dissection in the development of early and midterm redissection of the aortic root. Ann Thorac Surg. 2001;72:509-14.

25. Hata H, Takano H, Matsumiya G, Fukushima N, Kawaguchi N, Sawa Y. Late complications of gelatin-resorcin-formalin glue in the repair of acute type A aortic dissection. Ann Thorac Surg. 2007;83:1621-6.

26. Kunihara T, Neumann N, Kriechbaum SD, Aicher D, Schafers HJ. Aortic root remodeling leads to good valve stability in acute aortic dissection and preexistent root dilatation. J Thorac Cardiovasc Surg. 2016;152:430-6.e1.

27. Johnston DR, Soltesz EG, Vakil N, Rajeswaran J, Roselli EE, Sabik JF III, et al Long-term durability of bioprosthetic aortic valves: implications from 12,569 implants. Ann Thorac Surg. 2015;99:1239-47.

28. David TE, Armstrong S, Maganti M. Hancock II bioprosthesis for aortic valve replacement: the gold standard of bioprosthetic valves durability? Ann Thorac Surg. 2010;90:775-81.

29. Dvir D, Webb JG, Bleiziffer S, Pasic M, Waksman R, Kodali S, et al Transcatheter aortic valve implantation in failed bioprosthetic surgical valves. JAMA. 2014;312:162-70.

30. Bapat V, Davies W, Attia R, Hancock J, Bolter K, Young C, et al. Use of balloon expandable transcatheter valves for valve-in-valve implantation in patients with degenerative stentless aortic bioprostheses: technical considerations and results. J Thorac Cardiovasc Surg. 2014;148:917-22; discussion 922-4.

31. Luc JG, Shanks M, Tyrrell BD, Welsh RC, Butler CR, Meyer SR. Transcatheter valve-in-valve: a cautionary tale. Ann Thorac Surg. 2016;102:e211-3.

32. Chikwe J, Cavallaro P, Itagaki S, Seigerman M, Diluozzo G, Adams DH National outcomes in acute aortic dissection: influence of surgeon and institutional volume on operative mortality. Ann Thorac Surg. 2013;95: 1563-9.

33. Cabasa A, Pochettino A. Surgical management and outcomes of type A dissection-the Mayo Clinic experience. Ann Thorac Surg. 2016;5:296-309.

Key Words: aorta, aortic dissection, aortic root replacement, aortic root repair, reoperation, outcomes 
TABLE E1. Propensity score model

\begin{tabular}{|c|c|c|c|c|}
\hline & Estimate & Std. error & $\mathrm{z}$ value & $P$ value \\
\hline (Intercept) & -185.962 & 102.0621 & -1.822 & .07 \\
\hline Age & -0.02191 & 0.01191 & -1.839 & .07 \\
\hline White & 0.50212 & 0.30523 & 1.645 & .1 \\
\hline Heart failure & 0.6251 & 0.5888 & 1.062 & .3 \\
\hline Previous stroke & -0.30794 & 0.90452 & -0.34 & .7 \\
\hline $\begin{array}{l}\text { Chronic obstructive } \\
\text { pulmonary disease }\end{array}$ & -0.73875 & 0.51222 & -1.442 & .1 \\
\hline Coronary artery disease & 0.16517 & 0.50356 & 0.328 & .7 \\
\hline Operative year & 0.09234 & 0.05077 & 1.819 & .07 \\
\hline Bicuspid aortic valve & 2.32161 & 0.58275 & 3.984 & $<.001$ \\
\hline Redo sternotomy & -0.06223 & 0.72694 & -0.086 & .9 \\
\hline Extensive type A & -0.3219 & 0.4489 & -0.717 & .5 \\
\hline Preoperative shock & 0.86791 & 0.43745 & 1.984 & .05 \\
\hline $\begin{array}{l}\text { Preoperative neurologic } \\
\text { injury }\end{array}$ & -0.33832 & 0.51251 & -0.66 & .5 \\
\hline Malperfusion syndrome & 0.09229 & 0.34171 & 0.27 & .8 \\
\hline Severe AI on echo & 0.83221 & 0.30086 & 2.766 & .006 \\
\hline
\end{tabular}

